\title{
ORIGINAL ARTICLE Dietary energy density in young children across Europe
}

\author{
A Hebestreit ${ }^{1}$, C Börnhorst ${ }^{1}$, V Pala ${ }^{2}$, G Barba ${ }^{3}$, G Eiben ${ }^{4}$, T Veidebaum ${ }^{5}$, C Hadjigergiou ${ }^{6}$, D Molnár ${ }^{7}$, M Claessens $^{8}$, \\ JM Fernández-Alvira ${ }^{9}$ and I Pigeot ${ }^{1,10}$ on behalf of the IDEFICS consortium
}

OBJECTIVES: To describe energy density (ED; $\mathrm{kcal} \mathrm{g}^{-1}$ ) of dietary intake of European children. METHODS: From 16228 children who participated in the IDEFICS (Identification and prevention of Dietary- and lifestyle-induced health EFfects In Children and infantS) baseline examination, 8551 children with 24-h dietary recalls (24-HDR), with plausible reported energy intakes and complete covariate information were included in the present analysis. ED was calculated using two methods: (1) ED including solid foods $\left(E D_{F}\right)$ and (2) $E D$ including solid foods and energy-containing beverages $\left(E D_{F \& B}\right)$. Beverage energy was calculated in kcal per day. Dietary characteristics and body mass index (BMI) $z$-score of children aged 2 to $<6$ years and 6 to $<10$ years were compared between children with an overall EDF below the $<25$ th percentile, between the 25th and 75 th percentile as well as above the $>75$ th percentile. Standardised regression coefficients were estimated to assess the association between dietary characteristics, BMI z-score and ED of the diet.

RESULTS: Children with low $E D_{F}$ and $E D_{F \& B}$ diets consumed less energy but higher quantity of food and beverages than children with high $E D_{F}$ and $E D_{F \& B}$ diets. Consumption of caloric beverages decreased with increasing $E D_{F \& B}$ of the diet owing to the relatively low $E D$ of the beverages, in relation to solid foods. Generally, children with low $E D_{F}$ and $E D_{F \& B}$ diets showed healthier food choices than peers with higher $\mathrm{ED}_{\mathrm{F}}$ and $\mathrm{ED}_{\mathrm{F} \& \mathrm{~B}}$ diets. In this sample, $\mathrm{ED}_{\mathrm{F}}$ and $\mathrm{ED}_{\mathrm{F} \& \mathrm{~B}}$ were not associated with $\mathrm{BMI} Z$-score.

CONCLUSION: Health promotion strategies should proclaim lower ED diets by means of foods with high water and low fat content and mainly fruit and vegetable components. Excluding caloric beverages from $E D_{F}$ calculation is a useful method to avoid misinterpretation of true exposure to a high energy dense diet. We recommend excluding caloric beverages from $E_{F}$ calculation when investigating the effect of ED on a certain (health) outcome.

International Journal of Obesity (2014) 38, S124-S134; doi:10.1038/ijo.2014.143

\section{BACKGROUND}

High energy density of the diet was found to be associated with obesity in humans. ${ }^{1}$ In adults, there is strong evidence that diets high in energy density (ED, $\mathrm{kcal} \mathrm{g}^{-1}$ ) are associated with increased body weight, whereas diets low in ED encourage weight maintenance or even weight loss. ${ }^{2}$ The body of evidence for an association between high dietary ED and obesity is less strong in children and adolescents. ${ }^{3,4}$ High ED was found to be associated with greater intakes of energy, fat and added sugars, and with significantly lower intakes of fruits and vegetables. ${ }^{5}$ Children from families with a low socio-economic status were found to have an increased energy intake from larger portions of energy dense foods, whereas consuming large portions of low energy dense vegetables was associated with lower energy intake. ${ }^{6}$

These findings have led to the hypothesis that intake control is based upon the weight and volume of food (gastric filling) and not on its energy content. ${ }^{7,8}$ Energy density of a given amount of food (portion size) decreases with increasing water content, as water adds weight and not energy. ${ }^{9}$ The tendency to eat a consistent amount of foods by weight or volume on a day-to-day basis can be used to reduce ED: changes in moistness of the diet or its content of macronutrients or fibre can affect gastric emptying and release of satiety hormones. ${ }^{10}$ Also, energy intake from beverages has been observed to be associated with obesity in children if this contributes substantially to their daily energy intake. ${ }^{11}$ Foods and beverages affect satiety and energy intake differently and calculation of ED should, therefore, consider foods and beverages separately. Energy density is defined as the amount of energy per unit weight of food and can be calculated including or excluding caloric beverages. The present study aims to gain insight into the association between ED and caloric beverage intake using the two above mentioned ED calculation methods. Further, the association between ED and the consumption of specific food groups among European children was investigated as well as ED levels across European study centres. Extensive research on dietary intakes in 2-8-year-old US children has shown an overall increase of energy density of the diet during the past decades. ${ }^{4,12-14}$ Literature on ED of diets in larger young European populations is still scarce and covers mainly studies from United Kingdom, ${ }^{15,16}$ Spain, ${ }^{17}$ Denmark, ${ }^{18}$ Sweden ${ }^{19}$ and Germany. ${ }^{20}$ The present study aims to add new information on ED of foods consumed in children from various European regions: from Spain in the West to Estonia in the East and from Sweden in the North to Cyprus in the South. To date, no study has investigated ED of the diet of young children according to common definitions in a multinational European study, following a standardised study protocol.

${ }^{1}$ Leibniz Institute for Prevention Research and Epidemiology-BIPS, Bremen, Germany; ${ }^{2}$ Epidemiology and Prevention Unit, Department of Preventive \& Predictive Medicine, Fondazione IRCCS Istituto Nazionale dei Tumori, Milan, Italy; ${ }^{3}$ Epidemology \& Population Genetics, Institute of Food Sciences, National Research Council, Avellino, Italy; ${ }^{4}$ Department of Public Health and Community Medicine, University of Gothenburg, Sweden; ${ }^{5}$ Department of Chronic Diseases, National Institute for Health Development, Tallinn Estonia; ${ }^{6}$ Research and Education Institute of Child Health, Strovolos, Cyprus; ${ }^{7}$ Department of Pediatrics, University of Pécs, Pécs, Hungary; ${ }^{8}$ Department of Public Health, Ghent University, Ghent, Belgium; ${ }^{9}$ GENUD (Growth, Exercise, Nutrition and Development) Research Group, Faculty of Health Sciences, University of Zaragoza, Zaragoza, Spain and ${ }^{10}$ Department of Mathematics and Computer Science, University of Bremen, Bremen, Germany. Correspondence: Dr A Hebestreit, Leibniz Institute for Prevention Research and Epidemiology—BIPS, Achterstr. 30, D-28359 Bremen, Germany.

E-mail: hebestr@bips.uni-bremen.de 


\section{SUBJECTS AND METHODS}

\section{Study subjects}

A cohort of 16228 children aged 2-9 years was examined in a populationbased baseline survey in eight European countries ranging from North to South and from East to West (Sweden, Germany, Hungary, Italy, Cyprus, Spain, Belgium, Estonia) from autumn 2007 to spring 2008. The study was not designed to provide a representative sample for each country. Rather, the baseline survey $\left(T_{0}\right)$ was the starting point of a prospective cohort study with the largest European children's cohort established to date, called IDEFICS (Identification and prevention of Dietary- and lifestyleinduced health EFfects In Children and infantS) cohort.

Children in the defined age group who resided in the specific regions and who attended the selected pre-schools or kindergartens and primary schools (grades 1 and 2) were eligible for participation. Children were approached via schools and kindergartens to facilitate equal enrolment of all social groups. In addition to the signed informed consent given by parents, each child was asked to give verbal assent immediately before examination. In each country, participating centres obtained ethical approval from the local responsible authorities in accordance with the ethical standards laid down in the 1964 Declaration of Helsinki and its later amendments.

\section{Examinations}

The field methods comprised anthropometric measurements for standing height $(\mathrm{cm})$ using a Seca 225 stadiometer (seca, Birmingham, UK) according to international standards for anthropometric assessment ${ }^{21}$ and weight $(\mathrm{kg})$. Body weight was assessed in fasting children using a prototype of the TANITA BC 420 SMA digital scale (TANITA Europe GmbH, Sindelfingen, Germany) specifically adapted for children's feet. All measurements were performed in light clothing (for example, underwear). Body mass index (BMI) was calculated by dividing body weight in kilograms by squared body height in metres and then transformed to an age- and sex-specific $z$-score. ${ }^{22}$ BMI $z$-score is a measure of relative weight adjusted for child age and sex. BMI $z$-scores and weight groups (thin/ normal and overweight/ obese) were defined using age- and sex-specific cutoff values according to Cole and Lobstein. ${ }^{23}$

\section{The computer-based 24-h dietary recalls and school meal} assessments

In the IDEFICS study, dietary intake of the previous $24 \mathrm{~h}$ was assessed using the computer-assisted 24-h dietary recalls (24-HDR), called SACINA ('SelfAdministered Children and Infant Nutrition Assessment').24 Parents or other caregivers as proxy respondents for recalling children's diet required information on amount $(\mathrm{g})$ and type of all foods and drinks that were consumed during the previous day, starting with the first intake after waking up in the morning. Accurate estimation of portion size was assisted using standardised photographs. School meals, drinks and snacks consumed the day prior to the 24-HDR were assessed using a standardised observer sheet, completed by trained personnel. The SACINA software was based on the YANA-C ('Young adolescents' nutrition assessment on computer') system ${ }^{25}$ developed within the HELENA Study (http://www. helenastudy.com). Where required, proxies were assisted by the survey dietician or trained survey personnel when completing the 24-HDR.

Country-specific food composition tables (FCT) were used to match simple foods or European homogeneous multi-ingredient food items. ${ }^{26-30}$ Hungary included local recipes into the German FCT, Estonia combined the Norwegian and Finnish FCT, ${ }^{31,32}$ whereas Cyprus included foods from the German and Swedish FCT. All nutrients and energy values were expressed per $100 \mathrm{~g}$ edible portion. Standard units were taken from McCance and Widdowson's. ${ }^{33}$ As the Italian FCT provided nutrient data only for raw foods, a raw/cooked coefficient was applied when large raw/cooked deviations were expected after preparation owing to boiling or steaming. These raw/cooked coefficients (describing the weight change after preparation) were mainly applied for dried cereals (pasta, rice) and dried legumes. This procedure did not account for loss of vitamins and minerals during preparation.

The metabolisable energy values of foods and beverages were given in kilocalories (kcal). Contribution of non-starchy polysaccharides or sugar alcohols was not included in food energy calculation.

The IDEFICS study protocol required the assessment of one 24-HDR in all children and repeated 24-HDR interviews in a convenience sample. In the present study Monday to Thursday were defined as workdays ( $77 \%$ of all recalls), whereas Friday, Saturday and Sunday were defined as weekend days ( $23 \%$ respectively).

\section{Inclusion criteria for study sample}

From the full survey sample of 16228 children, subjects with one complete 24-HDR and covariate information required were included in the study final analysis $(N=9776)$. Highest educational level of the parents according to International Standard Classification of Education (ISCED97) was used as proxy indicator for socio-economic status of the family. ${ }^{34}$

Consistency of proxy-reported energy intake with age- and sex-related energy requirements was estimated using the ratio of proxy-reported energy intake over predicted basal metabolic rate. ${ }^{35}$ Finally, the proxyreported energy intake was classified according to adapted Goldberg cutoffs as under-reported, plausible reported and over-reported energy intake. ${ }^{36}$ Goldberg cutoff values were re-calculated for application in children ${ }^{37}$ using age- and sex-specific reference values. The sub-sample of plausible energy reporting (study sample, $N=8551$ ) was used in the main analysis (Figure 1). No substantial differences were observed when comparing main characteristics such as age and sex distribution, prevalence of overweight/obesity and ISCED level of the full survey sample and the sample presented here (results not shown).

\section{Quality management}

All measurements followed detailed standard operation procedures that were laid down in the general survey manual and finalised after the pretest of all survey modules. ${ }^{38}$ Field personnel from each study centre participated in central training and organised local training sessions thereafter. The coordinating centre conducted site visits to each study location during field surveys to check adherence of field staff to the standard operation procedures. Questionnaires were developed in English, translated to local languages, and then back-translated to check for translation errors. All study centres used the same technical equipment that was purchased centrally to maximise comparability of data.

Databases and computer-assisted questionnaires included automated plausibility checks. All numerical variables were entered twice independently. Inconsistencies identified by additional plausibility checks were rectified by the study centres.

The validity of proxy-reported energy intakes from the 24-HDR was investigated using comparison with total energy expenditure measured by the doubly labelled water technique. The instrument was found to be valid to assess El on group level. ${ }^{39}$

\section{Dietary data analysis}

Missing quantities or implausible values (above median+2.5 s.d. for single food items) that could not be corrected were imputed by country, food group and age-specific median intakes ( $0.01 \%$ of the entries). Incomplete 24-HDR and 24-HDR with four or more imputed values were excluded from the analysis. In total, 12 food groups assessed by the SACINA software were included in the present analysis: cereals \& cereal products, sugar \& sugar products, fat \& fat savoury sauces, fruits \& vegetables, meat \& meat products, fish \& fish products, egg, dairy products (excluding milk \& probiotic beverages), milk, chocolate milk \& probiotic beverages, vegetarian \& meat replacement products, mixed dishes as well as nonalcoholic beverages and soups. The amount of all consumed foods and beverages was recorded in grams ( $\mathrm{g}$ ). Dietary ED of foods and beverages was calculated as total energy intake (kcal per day) divided by total weight of daily food intake (g per day). ${ }^{40}$ In order to investigate associations between beverage energy and ED, ED was calculated using two definitions: (1) including solid food only $\left(E D_{F}\right)^{2,41}$ and (2) including solid foods and energy-containing beverages $\left(E D_{F \& B}\right){ }^{42}$ Energy-containing beverages comprised soups and bouillon, fruit/ vegetable juices, sugared carbonated/ soft/ isotonic drinks, milk, chocolate milk \& probiotic beverages. For both definitions, ED was calculated excluding non-caloric beverages, such as (table, mineral, natural) water, plain (herbal) tea and (surrogate) coffee and (carbonated) beverages with artificial sweeteners. Total daily beverage energy was calculated in kcal per day ${ }^{43}$ density of beverages was assumed to be $1.0 \mathrm{~g} \mathrm{ml}^{-1}$.

\section{Statistical analysis}

Descriptive statistics summarise daily beverage energy, $E D_{F}$ and $E D_{F \& B}$ according to the above mentioned definitions for pre-school children 


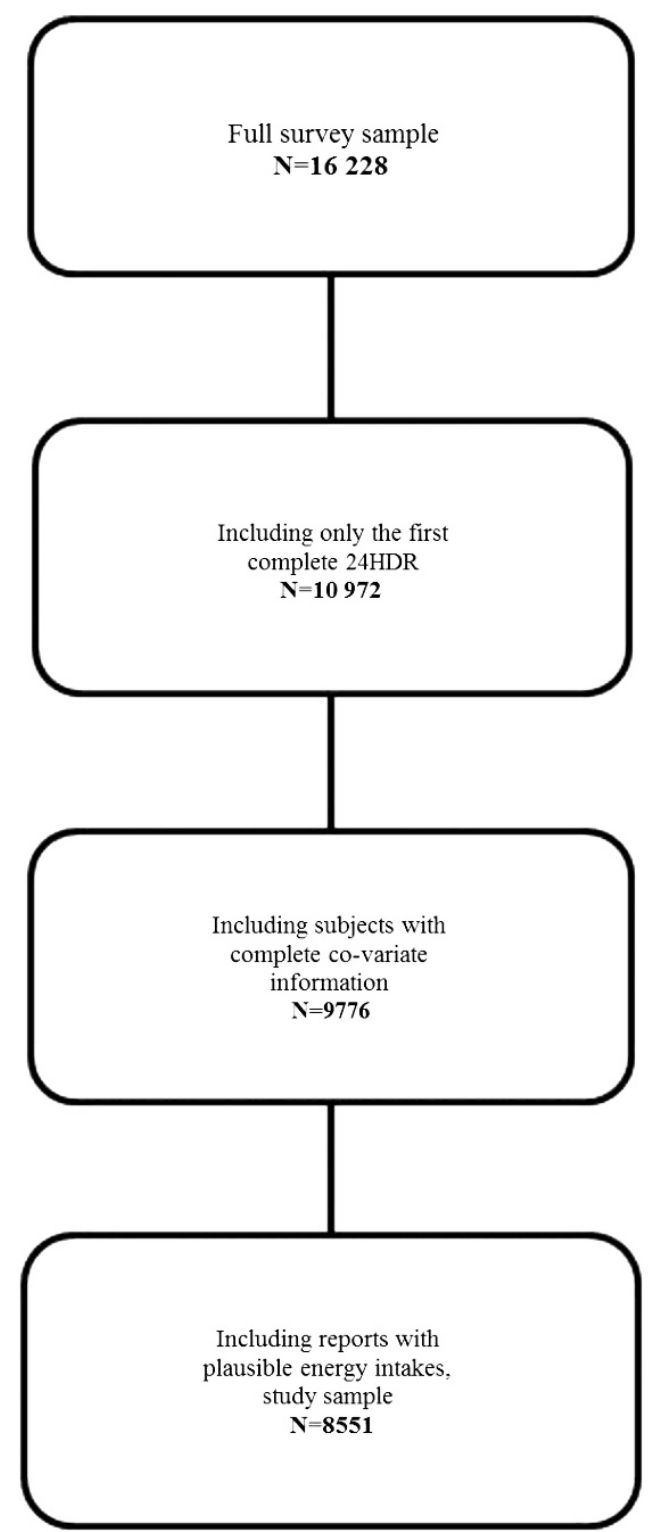

Figure 1. Inclusion criteria for study sample.

( 2 to $<6$ years) and primary school children ( 6 to $<10$ years) as well as for boys and girls.

Diet of children was classified in three ED categories based on the 25th and 75 th percentile of the study population. Means and $95 \%$ confidence intervals were calculated for all food groups intake as well as for dietary characteristics such as total food and beverage energy (kcal per day), total food and beverage intake ( $g$ per day), number of food items per day ( $N$ per day) and intakes from different food groups ( $\mathrm{g}$ per day) as well as for BMI $z$-score for pre-school children and primary school children with ED diets between the 0 to $<25$ th percentile, the 25th to 75th percentile and above the $>75$ th percentile including only children with plausible energy reports. The contributions of macronutrients to ED were investigated by calculating separately the ED due to fat, due to protein and due to carbohydrates.

For all food groups, the numbers of non-consumers on the single recall were calculated. In case the food group was consumed by $<30 \%$ of all study participants, the food group was considered as episodically consumed (fish \& fish products, egg, vegetarian \& meat replacement products, mixed dishes). These food groups were not individually evaluated, as a single day estimate of intake may not be interpretable. Of note, episodically consumed foods were not excluded from the energy intake and ED calculation. Associations between food intakes, BMI z-score (exposures) and ED (outcome) were investigated using multi-level regression models (SAS: PROC MIXED), statistical significance was set at $a=0.05$. All variables were standardised before performing the regression to ease later comparisons of the effect estimates by calculation of standardised beta-values. All models were run stratified by age group and were adjusted for sex, continuous age and ISCED97 $7^{34}$ and included a random effect for the study centre to account for the clustered study design. All statistical analyses were performed using SAS 9.2 (SAS Institute, Cary, NC, USA).

\section{RESULTS}

Study characteristics

The study population $(N=8551)$ consisted of $48.7 \%$ female participants; $80.4 \%$ of the study population was thin or normal weight, with a higher prevalence among pre-school children $(85.9 \%)$ than primary school children $(73.8 \%)$ (Table 1$)$. The highest proportion (20.1\%) of dietary data derived from Italian children and the lowest (4.0\%) from Belgian children.

Dietary energy density distribution

According to the two ED definitions, mean $\mathrm{ED}_{\mathrm{F}}$ was $1.88 \mathrm{kcal} \mathrm{g}^{-1}$ and $E D_{F \& B}$ was $1.32 \mathrm{kcal} \mathrm{g}^{-1}$ (Table 2). Food density of the diet was higher in school children $\left(E D_{F} 1.94 \mathrm{kcal} \mathrm{g}^{-1}\right)$ compared with preschoolers $\left(E D_{F} 1.81 \mathrm{kcal} \mathrm{g}^{-1}\right.$, respectively). That was true also for density including energy-containing beverages with $\mathrm{ED}_{\mathrm{F} \& \mathrm{~B}} 1.37$ kcalg for school children and $E D_{F \& B} 1.27 \mathrm{kcal} \mathrm{g}^{-1}$ for preschoolers, respectively. $\mathrm{ED}_{\mathrm{F}}$ and $\mathrm{ED}_{\mathrm{F} \& \mathrm{~B}}$ were similar in boys and girls $\left(E_{\mathrm{F}} 1.90 \mathrm{kcal} \mathrm{g}^{-1} ; 1.85 \mathrm{kcal} \mathrm{day}^{-1}\right.$ and $\mathrm{ED}_{\mathrm{F} \& \mathrm{~B}} 1.33 \mathrm{kcal} \mathrm{g}^{-1}$; $1.32 \mathrm{kcal} \mathrm{g}^{-1}$, respectively). Comparing study centres, $\mathrm{ED}_{\mathrm{F}}$ and $E D_{F \& B}$ were highest in Italian children $\left(2.29 \mathrm{kcal} \mathrm{g}^{-1}\right.$ and $\left.1.68 \mathrm{kcal} \mathrm{g}^{-1}\right)$, whereas $\mathrm{ED}_{\mathrm{F}}$ was lowest in Swedish children (1.56 $\left.\mathrm{kcal} \mathrm{g}^{-1}\right)$ and $E D_{\mathrm{F} \& \mathrm{~B}}$ was lowest in Estonia $\left(1.10 \mathrm{kcal} \mathrm{g}^{-1}\right)$ where the latter was at the same time the study centre with the highest mean daily beverage energy (381.07 kcal per day). Hungary reported the second highest intake of beverage energy (376.01 kcal per day) with a 'diluted' $E D_{\mathrm{F \& B}}$ value of $1.15 \mathrm{kcal} \mathrm{g}^{-1}$. When calculating ED including solid foods only, the Hungarian $E D_{F}$ increased to $1.87 \mathrm{kcal} \mathrm{g}^{-1}$ compared with the calculation including also caloric beverages. This is in contrast to Italy and Cyprus, which are the study centres with the highest and second highest $\mathrm{ED}_{\mathrm{F} \& \mathrm{~B}}\left(1.68 \mathrm{kcal} \mathrm{g}^{-1}\right.$ and $1.49 \mathrm{kcal} \mathrm{g}^{-1}$, respectively) and $\mathrm{ED}_{\mathrm{F}}(2.29$ $\mathrm{kcal} \mathrm{g}^{-1}$ and $1.95 \mathrm{kcal} \mathrm{g}^{-1}$, respectively) and at the same time reported the 7th and, respectively, 8th lowest energy intake from beverages (190.52 kcal day ${ }^{-1}$ and $177.96 \mathrm{kcal} \mathrm{day}^{-1}$ ) among all centres.

Beverage energy was higher in school children $(292 \mathrm{kcal}$ per day) than in pre-school children ( $284 \mathrm{kcal}$ per day) and higher in boys ( $301 \mathrm{kcal}$ per day) than in girls ( $274 \mathrm{kcal}$ per day).

As ED was comparable in boys and girls, subsequent analysis of food group consumption was not stratified by sex.

Dietary behaviours by energy density category and age group Tables 3 and 4 show means and 95\% confidence intervals of the dietary variables under investigation stratified by age group and by $\mathrm{ED}_{\mathrm{F}}$ or $\mathrm{ED}_{\mathrm{F} \& \mathrm{~B}}$ categories, respectively. In addition, standardised regression coefficients for the association between the dietary variables and the two ED measures are given. In both age groups, children with low $\mathrm{ED}_{\mathrm{F}}$ and $\mathrm{ED}_{\mathrm{F} \& \mathrm{~B}}$ diets ( 0 to $<25$ th percentile) consumed less food energy and less food \& beverage energy than children with high $\mathrm{ED}_{\mathrm{F}}$ and $\mathrm{ED}_{\mathrm{F} \& \mathrm{~B}}$ diets (above the $>75$ th percentile). Despite consuming less food and less food $\&$ beverage energy, these children consumed more grams of food and more grams of food \& beverages. As expected, children with the lowest $E_{F}$ and $E_{F \& B}$ consumed less fat but more protein and carbohydrates than children with higher $\mathrm{ED}_{\mathrm{F}}$ and $\mathrm{ED}_{\mathrm{F} \& \mathrm{~B}}$ diets. Daily energy intake from fat, protein and carbohydrates did not differ substantially between age groups and diets calculating 
Table 1. Descriptive characteristics of the study population (total group and stratified by age, total numbers and percentages

\begin{tabular}{|c|c|c|c|c|c|c|}
\hline & \multicolumn{2}{|c|}{$\begin{array}{c}\text { Children } 2 \\
\text { to }<6 \\
\text { years }\end{array}$} & \multicolumn{2}{|c|}{$\begin{array}{c}\text { Children } 6 \\
\text { to }<10 \\
\text { years }\end{array}$} & \multicolumn{2}{|c|}{ All } \\
\hline & $\mathrm{N}$ & $\%$ & $\mathrm{~N}$ & $\%$ & $\mathrm{~N}$ & $\%$ \\
\hline \multicolumn{7}{|l|}{ Sex of the child } \\
\hline Male & 2082 & 52.9 & 2308 & 50.0 & 4390 & 51.3 \\
\hline Female & 1856 & 47.1 & 2305 & 50.0 & 4161 & 48.7 \\
\hline \multicolumn{7}{|l|}{ Country } \\
\hline Italy & 776 & 19.7 & 947 & 20.5 & 1723 & 20.1 \\
\hline Germany & 650 & 16.5 & 843 & 18.3 & 1493 & 17.5 \\
\hline Hungary & 481 & 12.2 & 759 & 16.5 & 1240 & 14.5 \\
\hline Estonia & 639 & 16.2 & 548 & 11.9 & 1187 & 13.9 \\
\hline Sweden & 556 & 14.1 & 593 & 12.9 & 1149 & 13.4 \\
\hline Cyprus & 351 & 8.9 & 510 & 11.1 & 861 & 10.1 \\
\hline Spain & 289 & 7.3 & 271 & 5.9 & 560 & 6.5 \\
\hline Belgium & 196 & 5.0 & 142 & 3.1 & 338 & 4.0 \\
\hline \multicolumn{7}{|l|}{ ISCED level of parents ${ }^{\mathrm{a}}$} \\
\hline Primary education & 99 & 2.5 & 127 & 2.8 & 226 & 2.6 \\
\hline Lower secondary education & 338 & 8.6 & 434 & 9.4 & 772 & 9.0 \\
\hline $\begin{array}{l}\text { (Upper) secondary } \\
\text { education }\end{array}$ & 1376 & 34.9 & 1640 & 35.6 & 3016 & 35.3 \\
\hline $\begin{array}{l}\text { Post-secondary, non-tertiary } \\
\text { education }\end{array}$ & 692 & 17.6 & 777 & 16.8 & 1469 & 17.2 \\
\hline $\begin{array}{l}\text { First stage of tertiary } \\
\text { education }\end{array}$ & 1433 & 36.4 & 1635 & 35.4 & 3068 & 35.9 \\
\hline \multicolumn{7}{|l|}{ Weight status of the child ${ }^{\mathrm{b}}$} \\
\hline Thin/normal weight & 3381 & 85.9 & 3494 & 75.7 & 6875 & 80.4 \\
\hline Overweight/obese & 557 & 14.1 & 1119 & 24.3 & 1676 & 19.6 \\
\hline
\end{tabular}

$E D_{F}$ or $E D_{F \& B}$. Further, children with low $E D_{F}$ diets consumed less beverage energy (not apparent in the mean but in the standardised effect estimate) and less grams of energy-containing beverages than children in the highest $\mathrm{ED}_{\mathrm{F}}$ category, whereas children with low $E D_{F \& B}$ diets showed higher intakes of beverage energy and grams of energy-containing beverages than children in the highest $\mathrm{ED}_{\mathrm{F} \& \mathrm{~B}}$ category. Variations across the $\mathrm{ED}_{\mathrm{F}}$ categories were non-linear for beverage energy and energy-containing beverages among pre-school children. Children with high $\mathrm{ED}_{\mathrm{F} \& \mathrm{~B}}$ diets consumed more grams of non-caloric beverages than children with low $E D_{F \& B}$ diets. This association was not found in relation to variations in $\mathrm{ED}_{\mathrm{F}}$ diets alone. Mean $\mathrm{BMI} z$-score seemed to be associated with $E D_{F}$ and $E D_{F \& B}$ of the diet, which was no longer apparent in the standardised effect estimate. Total number of food items consumed per day was negatively associated with $E D_{F}$ and $E D_{F \& B}$ diets in both age groups.

Children with low $\mathrm{ED}_{\mathrm{F}}$ and $\mathrm{ED}_{\mathrm{F} \& \mathrm{~B}}(<25$ th percentile) diets showed lower intakes from cereals \& cereal products, sugar \& sugar products but higher intakes of fruits \& vegetables and dairy products than children with high $\mathrm{ED}_{\mathrm{F}}$ and $\mathrm{ED}_{\mathrm{F} \& \mathrm{~B}}(<75$ th percentile) diets in both age groups. Direction of association differed for fat \& fat savoury sauces, for meat and meat products and for milk, chocolate milk \& probiotic beverages depending on ED calculation. For instance, intake of milk, chocolate milk \& probiotic beverages was meaningfully higher in children with low $\mathrm{ED}_{\mathrm{F} \& \mathrm{~B}}$ diets compared with children with high $\mathrm{ED}_{\mathrm{F} \& \mathrm{~B}}$ diets. Variations across the $\mathrm{ED}_{\mathrm{F}}$ categories were not linear for intake of energy from carbohydrates, intake of cereals, sugar \& sugar products, fat $\&$ fat savoury sauces and of meat $\&$ meat products. Across $\mathrm{ED}_{\mathrm{F} \& \mathrm{~B}}$ categories only consumption of sugar \& sugar products was non-linear among age groups. Of note, fish \& fish products, egg, vegetarian \& meat replacement products, mixed dishes were considered being episodically consumed foods and were therefore excluded from the results and from Tables 3 and 4.

\section{DISCUSSION}

Although calculation of energy density of foods strongly differs between studies, most researchers suggest the exclusion of all beverages, because beverages tend to 'water down' the true ED of a diet, which may lead to misinterpretation of the exposure to a high energy dense diet. ${ }^{43,44}$ Aim of the present study was to compare two different ED calculations (with or without beverage energy) and to investigate the association between $\mathrm{ED}$ calculations $\left(\mathrm{ED}_{\mathrm{F}}\right.$ and $\left.\mathrm{ED}_{\mathrm{F} \& \mathrm{~B}}\right)$ and food group consumption in 2-9-year-old children.

Centres with a high consumption of caloric beverages showed lower $\mathrm{ED}_{\mathrm{F} \& \mathrm{~B}}$ values compared with $\mathrm{ED}_{\mathrm{F}}$ values, highlighting that caloric beverages lower the observed ED values by contributing more weight than energy to the ED calculation than solid foods. Both high ED diets and high intakes of caloric beverages have been reported to be associated with high energy intakes and were suggested to be associated with childhood obesity. ${ }^{45}$ When using $\mathrm{ED}_{\mathrm{F} \& \mathrm{~B}}$ calculation method (including caloric beverages), this association seems to be contradictive as high intakes of caloric beverages reduced the $E D_{F \& B}$ value, owing to their relatively high water content. The inclusion of caloric beverages in the ED calculation may consequently attenuate or even reverse the expected positive association between ED and weight status. Hence, for investigating the associations between beverage energy, ED and an outcome of specific interest, beverage energy should be calculated directly and $\mathrm{ED}_{\mathrm{F}}$ should be derived excluding caloric beverages.

Not only directions of association between $E D_{F}, E D_{F \& B}$ and caloric beverages but also strength of association between ED and food group intake differ, depending on the way ED was calculated, as to be seen in the consumption of, for example, milk, chocolate milk \& probiotic beverages. Consumption of caloric beverages decreased strongly across the $\mathrm{ED}_{\mathrm{F} \& \mathrm{~B}}$ categories, which may be explained by the relatively (compared with solid foods) low ED of caloric beverages. Variations across $\mathrm{ED}_{\mathrm{F}}$ categories were nonlinear, which may be explained by the exclusion of caloric beverages.

In our study, children with low $\mathrm{ED}_{\mathrm{F}}$ and $\mathrm{ED}_{\mathrm{F} \& \mathrm{~B}}$ diets show substantially healthier food choices than children with higher $E D_{F}$ and $E D_{F \& B}$ diets. Healthy food choices-such as high-nutrient dense and low ED foods-may be the result of successful health education ${ }^{46}$ and of healthy food offers at home, ${ }^{47}$ in kindergarten and school. Interestingly, dietary patterns characterised by snacking, sweet and fatty food groups have recently been found to be associated with weight gain in the IDEFICS cohort, whereas dietary patterns rich in fruit, vegetables, wholemeal cereals and plain milk were found protective against overweight/obesity. ${ }^{48,49}$ Nevertheless, no association between ED and BMI $z$-score was found in the present study.

Total beverage energy (kcal per day) and total food \& beverage energy (kcal per day) was lower in the IDEFICS study compared with beverage energy in the cross-sectional US National Health and Nutrition Examination Survey (NHANES) of 2-8-year-old US children. ${ }^{5}$ In both age groups, total food energy (kcal per day) and food intake ( $\mathrm{g}$ per day) of the NHANES sample were slightly higher in all ED categories than in the IDEFICS study, which can be explained with the generally higher $E D_{F}$ of the US diet.

In the IDEFICS study, mean $\mathrm{ED}_{\mathrm{F}}$ was $1.81 \mathrm{kcal} \mathrm{g}^{-1}$ for pre-school children from 2 to $<6$ years of age and $1.94 \mathrm{kcal} \mathrm{g}^{-1}$ for school children from 6 to $<10$ years of age; subsequently $E_{F}$ was lower than in a 2007 published US survey, ${ }^{13}$ where 3, 4, 5 and 6-year-old children showed a mean daily ED of $2.14 \mathrm{kcal} \mathrm{g}^{-1}, 2.23 \mathrm{kcal} \mathrm{g}^{-1}$, 
Table 2. Mean energy intake from beverages and mean energy densities (ED) according to different methods: including solid food only $\left(E D_{F}\right)$ and including solid foods and energy-containing beverages $\left(E D_{F \& B}\right)^{a, b}$

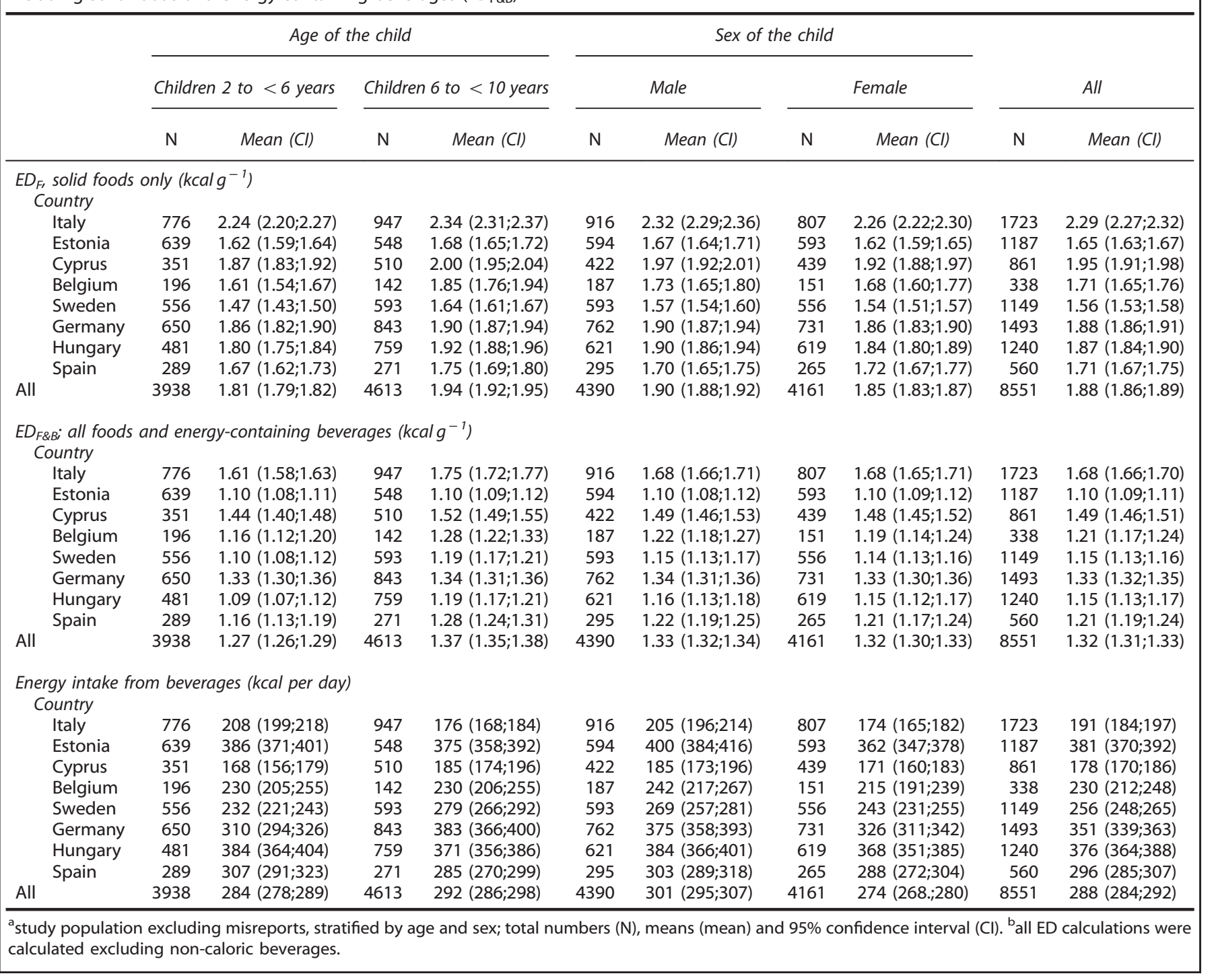

$2.17 \mathrm{kcal} \mathrm{g}^{-1}$ and $2.31 \mathrm{kcal} \mathrm{g}^{-1}$, respectively. Daily $E D_{\mathrm{F}}$ of the NHANES sample was generally higher than daily $E D_{F}$ intakes in the IDEFICS study: ${ }^{14} 1971-19742.09 \mathrm{kcal} \mathrm{g}^{-1}, 1976-1980$ $2.13 \mathrm{kcal} \mathrm{g}^{-1}, 1988-19942.11 \mathrm{kcal} \mathrm{g}^{-1}, 1999-20022.23 \mathrm{kcal} \mathrm{g}^{-1}$ and $2003-20082.22 \mathrm{kcal} \mathrm{g}^{-1}$. Overall ED (per eating occasion) increased from $2.00 \mathrm{kcal} \mathrm{g}^{-1}$ to $2.19 \mathrm{kcal} \mathrm{g}^{-1}$ over a 30 -year period in 2 to $<12$-year-old US children. ${ }^{12}$ In the 1980 s, daily ED $D_{F}$ of the German National Food Consumption Study (NVS; 1985-1988) was lower (median $\mathrm{ED}_{\mathrm{F}} 1.7 \mathrm{kcal} \mathrm{g}^{-1}$ ) among school children than 2007/2008 in the IDEFICS study (mean EDF $1.94 \mathrm{kcal} \mathrm{g}^{-1}$ ) and even lower than the mean $\mathrm{ED}_{\mathrm{F}}$ of the German IDEFICS children $\left(1.88 \mathrm{kcal} \mathrm{g}^{-1}\right)$. In the nutrition module of the German Health Interview and Examination Survey For Children and Adolescents (EsKiMo, 2006) $\mathrm{ED}_{\mathrm{F}}$ (median $\mathrm{ED}_{\mathrm{F}} 1.5 \mathrm{kcal} \mathrm{g}^{-1}$ ) was lower in school children compared with the corresponding age group of the IDEFICS study. ${ }^{20}$ The overall higher EDF of the NHANES sample may be explained by the 2-year older US study sample compared with the IDEFICS sample or by a truly higher ED of the US diet. Interestingly, the three top-ranked food groups (except beverages) consumed by children of the different samples were comparable and did not shed light on diverging food choices. Namely the three top-ranked food groups of the NHANES sample
(2-8 years) were fruits/vegetables, grains/equivalents and dairy products (including milk and cheese), ${ }^{5}$ of NVS/ EsKiMo (6-11 years) were milk/dairy products, bread/pastries and fruits/ nuts $^{20}$ and of IDEFICS (2-9 years) were milk (including chocolate milk \& probiotic beverages), cereals/cereal products and fruit and vegetables.

In the present study, $E D_{F}, E D_{F \& B}$ and beverage energy were examined to investigate differences among study centres. We found country-specific ED $D_{F}$ from 1.95 and $2.29 \mathrm{kcal} \mathrm{g}^{-1}$ for Cyprus and Italy in the South to $1.56 \mathrm{kcal} \mathrm{g}^{-1}$ for Sweden in the North, from $1.71 \mathrm{kcal} \mathrm{g}^{-1}$ for Spain in the West to $1.65 \mathrm{kcal} \mathrm{g}^{-1}$ Estonia in the East. These findings are in line with the ecological distribution of overweight and obesity prevalence among children in the IDEFICS study (see Ahrens et al. on prevalence of overweight; this issue), even though no association between BMI $z$-score and ED was found in the present study.

The generally lower $\mathrm{ED}_{\mathrm{F}}$ among European children should continue $^{50}$ as reducing the ED of the diet is a suitable strategy to reduce weight or maintain a healthy body weight without counting calories or fat grams. In this regard, energy density standards are useful; they do not depend on an individual's 


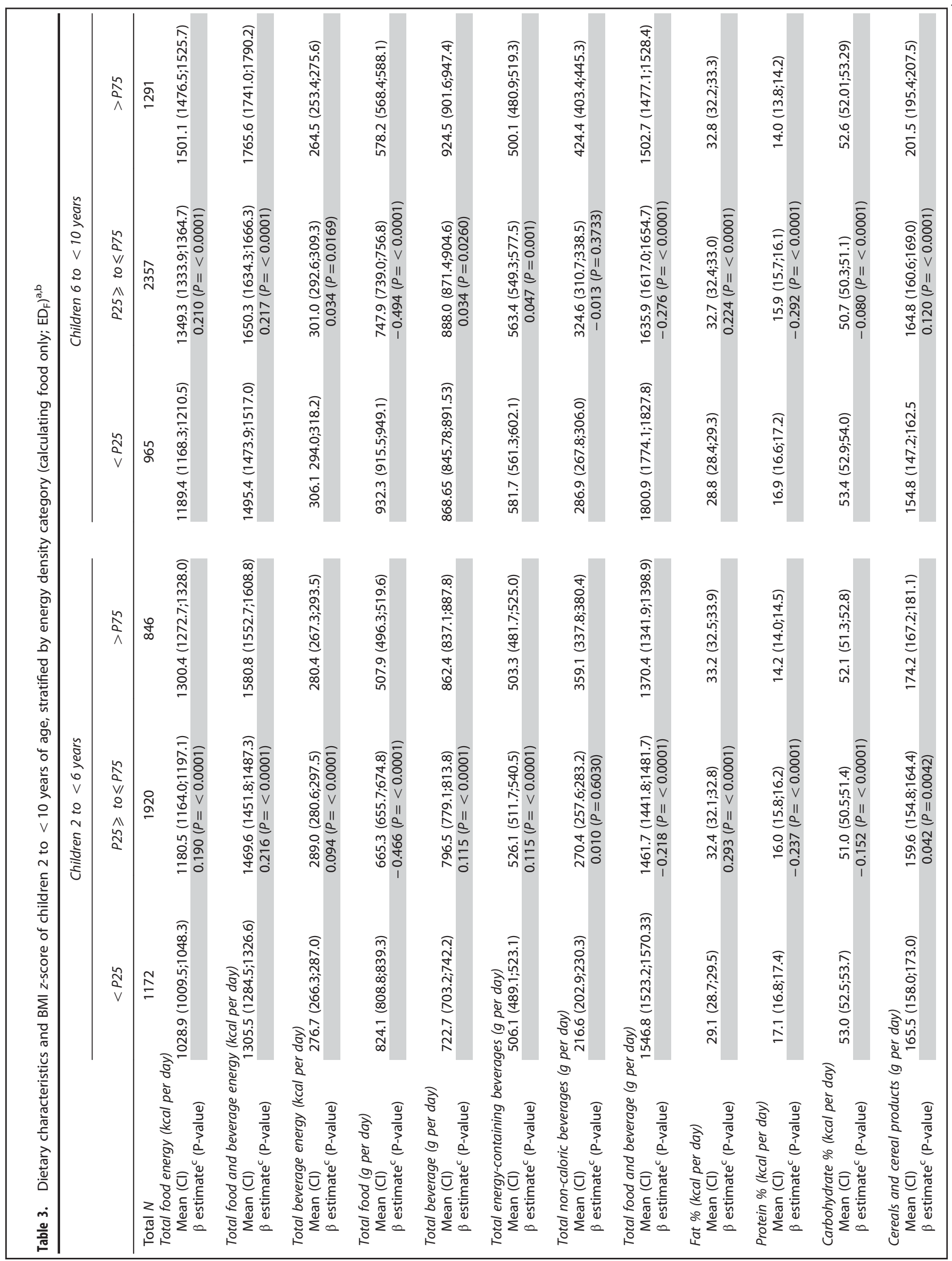




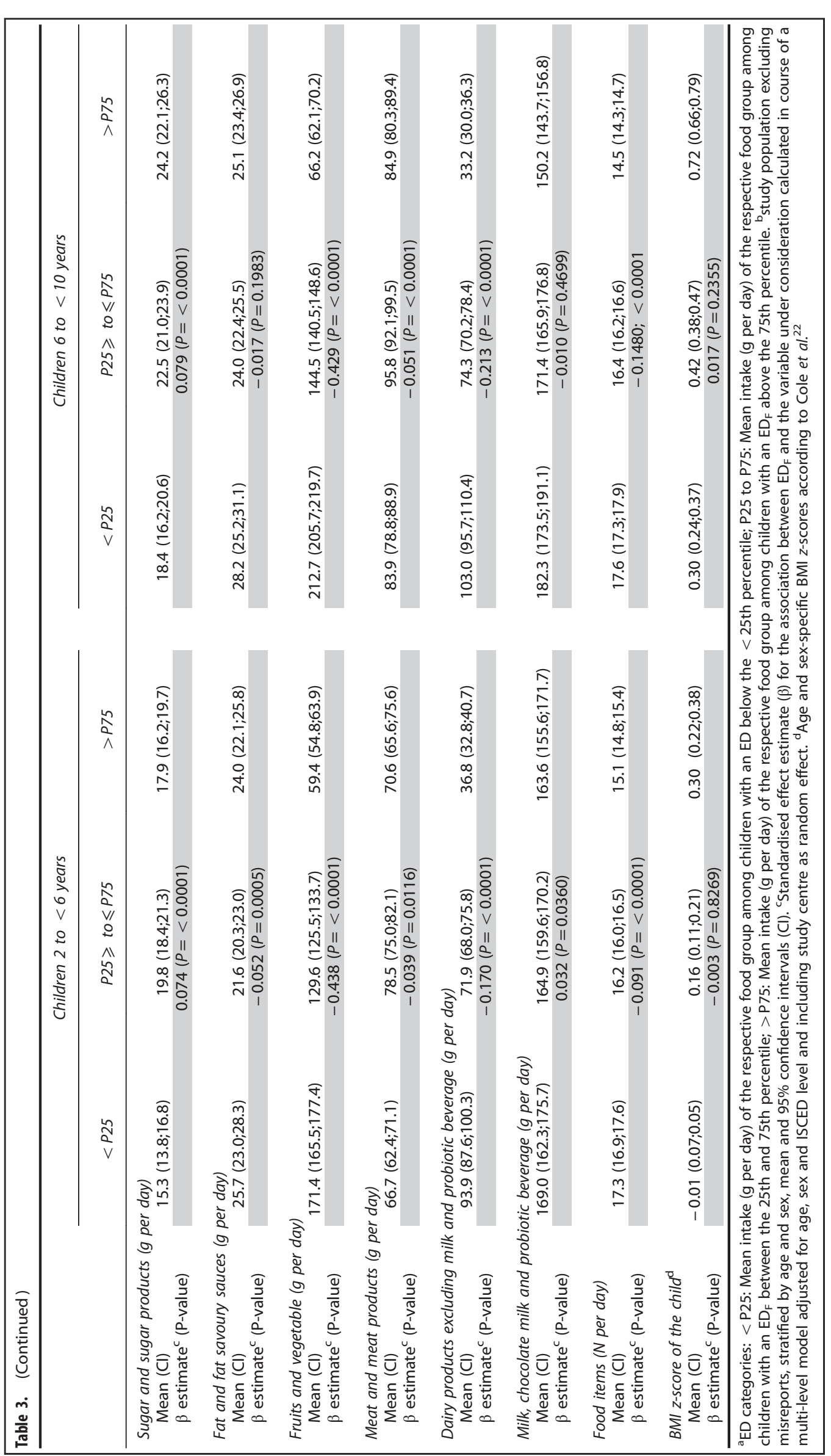




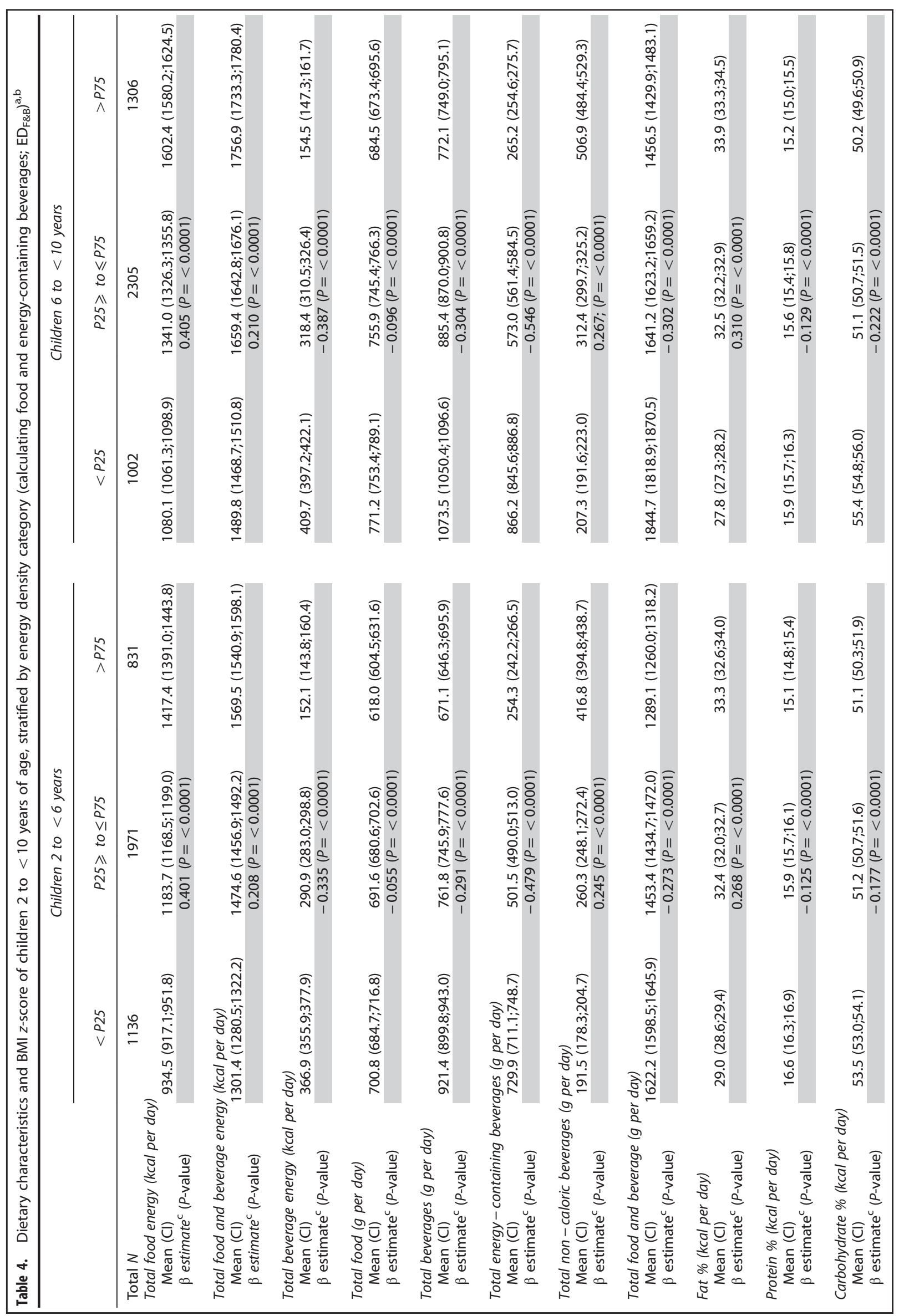




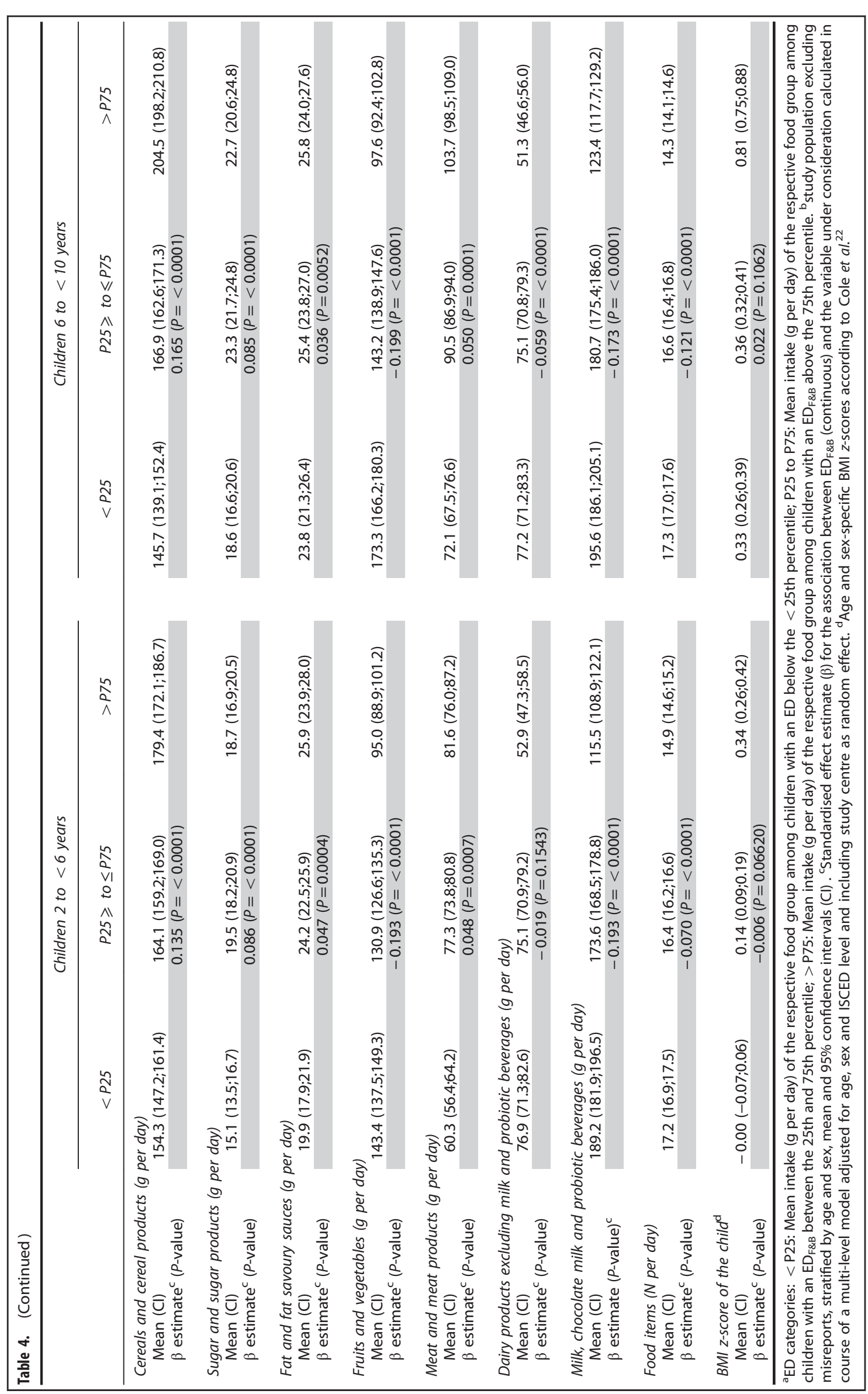


energy requirement, ${ }^{41}$ which is difficult to measure with a reasonable degree of accuracy.

\section{Limitations and strengths}

In the IDEFICS study, mainly the parents completed the 24-HDR for the children. Proxy-reporting relates to the number of meals under parental control; incomplete reporting of food and beverage consumption may contribute towards reporting bias. ${ }^{51}$ Thus one important factor limiting completeness of food reporting in the IDEFICS study was the consumption of foods without parental control, such as meals and beverages consumed in school and/or pre-school. The collection of dietary information by observation using trained personnel during school time for the day prior to the $24-\mathrm{HDR}^{24}$ helped to overcome the problem of incomplete 24-HDR. Also parents had the possibility to indicate meals outside control. Later, 24-HDR with missing meals were excluded from the study sample. Even though we excluded incomplete recalls, our results indicate a certain degree of misreporting through missing dietary information for snacking or out of home. ${ }^{51}$

The accurate estimation of portion sizes also poses a challenge to untrained interviewees. Photographs in automated 24-HDR have been proven to be useful for accurate portion size estimation among adults. ${ }^{52}$ In SACINA, quantities were mainly assessed by photos of serving sizes, standard portions, customary packing size and foods in pieces or slices. However, inaccuracy of portion size estimation cannot be entirely ruled out and may have led to misreports of energy intake in the survey sample.

The present analysis is based on one 24-HDR per child, which is a limitation, as a single day may not reflect the individual usual intake due to the daily variation in diet. However, single 24-HDR are still considered as a valid tool for the estimation of population means as random errors cancel out on group level. ${ }^{53}$ Main proportion (77\%) of 24-HDR was collected on workdays. Even though IDEFICS children tend to consume, for example, more sugar, sugar-rich foods and beverages during weekends compared with workdays, energy intake did not differ significantly between workdays and weekend days. ${ }^{54}$ Still, slightly higher ED levels during weekends cannot be precluded, which may have led to a small underestimation of the present ED values.

Nevertheless, the IDEFICS study permits a deeper insight into $E D_{F}, E D_{F \& B}$ and food choices of 2-9-year-old children across Europe. The large sample size comprising data from eight European countries, the strictly standardised data assessment, documentation and data cleaning processing guarantee the highest possible data quality.

\section{CONCLUSION}

To conclude, calculation of ED should exclude all types of beverages (energy and amount) as inclusion of caloric beverages may attenuate of even reverse expected associations with health outcomes. The European IDEFICS study did not find any association between dietary ED and BMI $z$-score in children, but an association between total food energy intake (kcal per day) and total food \& beverage energy intake (kcal per day) and ED of the diet. Pre-school and school children with low $E_{F}$ and $E D_{F \& B}$ diets showed generally healthier food choices than children with higher $\mathrm{ED}_{\mathrm{F}}$ and $\mathrm{ED}_{\mathrm{F} \& \mathrm{~B}}$ : they consume less fat, less cereal and their products, less sugar but more protein and carbohydrates, more fruits and vegetables and more dairy products than children with high $E D_{F}$ and $E D_{F \& B}$ diets. The generally lower dietary $E D_{F}$ among European children compared with former and recent US data should proceed and the promotion of a large diversity of foods with high water and low fat content and mainly fruit and vegetable components should, therefore, be promoted in nutrition campaigns among children.

\section{CONFLICT OF INTEREST}

The authors declare no conflict of interest.

\section{ACKNOWLEDGEMENTS}

This work was done as part of the IDEFICS Study (www.idefics.eu). We gratefully acknowledge the financial support of the European Community within the Sixth RTD Framework Programme Contract No. 016181 (FOOD). We thank the IDEFICS children and their parents for participating in this extensive examination. We are grateful to the Volkswagen Foundation that financially supported the production of this supplement.

\section{DISCLAIMER}

This manuscript represents original work that has not been published previously and is currently not considered by another journal. The information in this document reflects the author's view and is provided as is. Each author has seen and approved the contents of the submitted manuscript. All authors contributed to conception and design, acquisition of data, analysis or interpretation of data. Final approval of the version published was given by all the authors.

\section{REFERENCES}

1 Perez-Escamilla R, Obbagy JE, Altman JM, Essery EV, McGrane MM, Wong YP et al. Dietary energy density and body weight in adults and children: a systematic review. J Acad Nutr Diet 2012; 112: 671-684.

2 Ledikwe JH, Rolls BJ, Smiciklas-Wright H, Mitchell DC, Ard JD, Champagne $\mathrm{C}$ et al. Reductions in dietary energy density are associated with weight loss in overweight and obese participants in the PREMIER trial. Am J Clin Nutr 2007; 85: 1212-1221.

3 Johnson L, Mander AP, Jones LR, Emmett PM, Jebb SA. A prospective analysis of dietary energy density at age 5 and 7 years and fatness at 9 years among UK children. Int J Obes (Lond) 2008; 32: 586-593.

4 Mendoza JA, Drewnowski A, Cheadle A, Christakis DA. Dietary energy density is associated with selected predictors of obesity in U.S. Children. J Nutr 2006; 136: 1318-1322.

5 Vernarelli JA, Mitchell DC, Hartman TJ, Rolls BJ. Dietary energy density is associated with body weight status and vegetable intake in U.S. children. $J$ Nutr 2011; 141: 2204-2210.

6 Colapinto CK, Fitzgerald A, Taper LJ, Veugelers PJ. Childre's preference for large portions: prevalence, determinants, and consequences. J Am Diet Assoc 2007; 107: 1183-1190.

7 Westerterp-Plantenga MS. Analysis of energy density of food in relation to energy intake regulation in human subjects. Br J Nutr 2001; 85: 351-361.

8 Rolls BJ, Roe LS. Effect of the volume of liquid food infused intragastrically on satiety in women. Physiol Behav 2002; 76/4-5: 623-631.

9 Kral TV, Rolls BJ. Energy density and portion size: their independent and combined effects on energy intake. Physiol Behav 2004; 82: 131-138.

10 Lejeune MP, Westerterp KR, Adam TC, Luscombe-Marsh ND, Westerterp-Plantenga MS. Ghrelin and glucagon-like peptide 1 concentrations, 24-h satiety, and energy and substrate metabolism during a high-protein diet and measured in a respiration chamber. Am J Clin Nutr 2006; 83: 89-94.

11 Ludwig DS, Peterson KE, Gortmaker SL. Relation between consumption of sugarsweetened drinks and childhood obesity: a prospective, observational analysis. Lancet 2001; 357: 505-508.

12 Duffey KJ, Popkin BM. Causes of increased energy intake among children in the U. S., 1977-2010. Am J Prev Med 2013; 44: e1-e8.

13 Kral TV, Stunkard AJ, Berkowitz RI, Stallings VA, Brown DD, Faith MS. Daily food intake in relation to dietary energy density in the free-living environment: a prospective analysis of children born at different risk of obesity. Am J Clin Nutr 2007; 86: 41-47.

14 Kant AK, Graubard BI. Family income and education were related with 30-year time trends in dietary and meal behaviors of American children and adolescents. J Nutr 2013; 143: 690-700.

15 Johnson L, Mander AP, Jones LR, Emmett PM, Jebb S. Energy-dense, low-fiber, high fat dietary pattern is associated with increased fatness in childhood. Am $J$ Clin Nutr 2008; 87: 846-854.

16 Gibson SA. Associations between energy density and macronutrient composition in the diets of pre-school children: sugars vs. starch. Int J Obes Relat Metab Disord 2000; 24: 633-638.

17 Marti-Henneberg C, Capdevila F, Arija V, Perez S, Cuco G, Vizmanos B et al. Energy density of the diet, food volume and energy intake by age and sex in a healthy population. Eur J Clin Nutr 1999; 53: 421-428. 
18 Rothausen BW, Matthiessen J, Andersen LF, Brockhoff PB, Tetens I. Dietary patterns on weekdays and weekend days in 4-14-year-old Danish children. $\mathrm{Br} J$ Nutr 2013; 109: 1704-1713.

19 Patterson E, Warnberg J, Poortvliet E, Kearney JM, Sjostrom M. Dietary energy density as a marker of dietary quality in Swedish children and adolescents: the European Youth Heart Study. Eur J Clin Nutr 2010; 64: 356-363.

20 Stahl A, Vohmann C, Richter A, Heseker H, Mensink GB. Changes in food and nutrient intake of 6- to 17-year-old Germans between the 1980s and 2006. Public Health Nutr 2009; 12: 1912-1923.

21 Marfell-Jones M, Olds T, Stewart A, Carter L. International Standards for Anthropometric Assessment. International Society for the Advancement of Kinanthropometry: Potchefstroom, South Africa, 2006.

22 Cole TJ, Freeman JV, Preece MA. British 1990 growth reference centiles for weight, height, body mass index and head circumference fitted by maximum penalized likelihood. Stat Med 1998; 17: 407-429.

23 Cole TJ, Lobstein T. Extended international (IOTF) body mass index cut-offs for thinness, overweight and obesity. Pediatr Obes 2012; 7: 284-294.

24 Hebestreit A, Reinecke A, Huybrechts I. Computer based 24-hour dietary recall: the SACINA program. In: Measurement Tools for a Health Survey on Nutrition, Physical Activity and Lifestyle in Children: The European IDEFICS Study. Springer: New York, Dordrecht, Heidelberg, London, 2013.

25 Vereecken CA, Covents M, Sichert-Hellert W, Alvira JM, Le DC, de HS et al. Development and evaluation of a self-administered computerized 24-h dietary recall method for adolescents in Europe. Int J Obes (Lond) 2008; 32 (Suppl 5): S26-S34.

26 National Food Administration. Swedish Food Database. http://www.slv.se/. 23 February 2007

27 Max Rubner-Institut. Bundeslebensmittelschlüssel des Bundesministeriums für Ernährung, Landwirtschaft und Verbraucherschutz. www.blsdb.de. 2008.

28 Centre d'Ensenyament Superior de Nutrició i Dietètica (CESNID). TABLAS DE COMPOSICIÓN DE ALIMENTOS DEL CESNID. Mc Graw Hill. Edicions Universitat de Barcelona, 2004.

29 Belgian Federal Public Service. Le belge de composition des aliments Nubel http://www.nubel.com/ 2001.

30 European Institute of Oncology. Food Composition Database for Epidemiological Studies in Italy (Banca Dati di Composizione degli Alimenti per Studi Epidemiologici in Italia-BDA) 2013.

31 Norwegian Food Composition database (MVT-06), http://www.norwe gianfoodcomp.no, 2006.

32 Finnish Food Composition Table, http://www.ktl.fi/Fineli, 2000.

33 McCance, Widdowson. The Composition of Foods. 6 edn : Cambride, London. The Royal Society of Chemistry and the Food Standards Agency, 2002.

34 UNESCO. International Standard Classification of Education, www.uis.unesco.org, 2010.

35 Schofield WN. Predicting basal metabolic rate, new standards and review of previous work. Hum Nutr Clin Nutr 1985; 39 (Suppl 1): 5-41.

36 Goldberg GR, Black AE, Jebb SA, Cole TJ, Murgatroyd PR, Coward WA et al. Critical evaluation of energy intake data using fundamental principles of energy physiology: 1. Derivation of cut-off limits to identify under-recording. Eur J Clin Nutr 1991; 45: 569-581.

37 Börnhorst C, Huybrechts I, Ahrens W, Eiben G, Michels N, Pala V et al. Prevalence and determinants of misreporting among European children in proxy-reported $24 \mathrm{~h}$ dietary recalls. Br J Nutr 2012; 109: 1257-1265.

38 Suling M, Hebestreit A, Peplies J, Bammann K, Nappo A, Eiben G et al. Design and results of the pretest of the IDEFICS study. Int J Obes (Lond) 2011; 35 (Suppl 1): S30-S44.

39 Börnhorst C, Bel-Serrat S, Pigeot I, Huybrechts I, Ottavaere C, Sioen I et al. Validity of 24-h recalls in (pre-)school aged children: Comparison of proxy- reported energy intakes with measured energy expenditure. Clin Nutr 2013; 33 79-84.

40 Monsivais $\mathrm{P}$, Drewnowski A. Lower-energy-density diets are associated with higher monetary costs per kilocalorie and are consumed by women of higher socioeconomic status. J Am Diet Assoc 2009; 109: 814-822.

41 Schusdziarra V, Hausmann M, Wiedemann C, Hess J, Barth C, Wagenpfeil S et al. Successful weight loss and maintenance in everyday clinical practice with an individually tailored change of eating habits on the basis of food energy density. Eur J Nutr 2011; 50: 351-361.

42 McCaffrey TA, Rennie KL, Kerr MA, Wallace JM, Hannon-Fletcher MP, Coward WA et al. Energy density of the diet and change in body fatness from childhood to adolescence; is there a relation? Am J Clin Nutr 2008; 87: 1230-1237.

43 Johnson L, Wilks DC, Lindroos AK, Jebb SA. Reflections from a systematic review of dietary energy density and weight gain: is the inclusion of drinks valid? Obes Rev 2009; 10: 681-692.

44 Ledikwe JH, Blanck HM, Khan LK, Serdula MK, Seymour JD, Tohill BC et al. Dietary energy density determined by eight calculation methods in a nationally representative United States population. J Nutr 2005; 135: 273-278.

45 Lee HS, Kwon SO, Lee Y. Weight status and dietary factors associated with sugarsweetened beverage intake among korean children and adolescents - Korea National Health and Nutrition Examination Survey, 2008-2011. Clin Nutr Res 2013; 2: $135-142$.

46 Hebestreit A, Keimer KM, Hassel H, Nappo A, Eiben G, Fernandez JMet al. What do children understand? Communicating health behavior in a European multicenter study. J Public Health 2010; 18: 391-401.

47 Zuercher JL, Wagstaff DA, Kranz S. Associations of food group and nutrient intake, diet quality, and meal sizes between adults and children in the same household: a cross-sectional analysis of U.S. households. Nutr J 2011 10: 131.

48 Pala V, Lissner L, Hebestreit A, Lanfer A, Sieri S, Siani A et al. Dietary patterns and longitudinal change in body mass in European children: a follow-up study on the IDEFICS multicenter cohort. Eur J Clin Nutr 2013; 67: 1042-1049.

49 Tognon G, Hebestreit A, Lanfer A, Moreno LA, Pala V, Siani A et al. Mediterranean diet, overweight and body composition in children from eight European countries: Cross-sectional and prospective results from the IDEFICS study. Nutr Metab Cardiovasc Dis 2013; 24: 205-213.

50 Rolls BJ, Drewnowski A, Ledikwe JH. Changing the energy density of the diet as a strategy for weight management. J Am Diet Assoc 2005; 105 (Suppl 1): S98-103.

51 Livingstone MB, Robson PJ. Measurement of dietary intake in children. Proc Nutr Soc 2000; 59: 279-293.

52 Subar AF, Crafts J, Zimmerman TP, Wilson M, Mittl B, Islam NG et al. Assessment of the accuracy of portion size reports using computer-based food photographs aids in the development of an automated self-administered 24-hour recall. $J$ Am Diet Assoc 2010; 110: 55-64.

53 Rutishauser IH. Dietary intake measurements. Public Health Nutr 2005; 8: 1100-1107.

54 Svensson A, Larsson CL, Eiben G, Lanfer A, Pala V, Hebestreit A et al. European childrens's intake of sugars and sugar-rich foods and drinks on weekdays versus weekends-the IDEFICS Study. Eur J Clin Nutr 2014; 68: 822-828.

(c) (i) $(-)$ This work is licensed under a Creative Commons Attribution(c) $\left.{ }_{\mathrm{BY}}\right)_{\mathrm{ND}}$ NonCommercial-NoDerivs 4.0 International License. The images or other third party material in this article are included in the article's Creative Commons license, unless indicated otherwise in the credit line; if the material is not included under the Creative Commons license, users will need to obtain permission from the license holder to reproduce the material. To view a copy of this license, visit http:// creativecommons.org/licenses/by-nc-nd/4.0/ 